\title{
Characterization and fungistatic activity of Eucalyptus globulus leaf extract mediated phytosynthesized silver nanoparticles
}

\author{
Thejesh Kumar M. P' . and Rajkumar H. Garampalli ${ }^{2} *$ \\ ${ }^{1,2}$ Department of Studies in Botany, University of Mysore, Manasagangotri, Mysore - 570 006, Karnataka State, India \\ *Corresponding Author: dr.hgrajkumar@botany.uni-mysore.ac.in, Tel: +91-821-2419757
}

Available online at: www.isroset.org

Received: 02/Feb/2019, Accepted: 10/Feb/2019, Online: 28/Feb/2019

\begin{abstract}
In the present study silver nanoparticles were synthesized through green approach using leaf extract of Eucalyptus globules and confirmed by change in colour of reaction mixture, the peak obtained at $425 \mathrm{~nm}$ in UV-visible spectroscopic study and characterized by XRD, DLS, SEM, EDAX and FTIR for their structure, size, shape and possible biomolecules responsible for the reduction of silver ion to silver nanoparticles. XRD spectrum confirmed the particles were face centered cubic in nature with an average particle size of $25 \mathrm{~nm}$ which is in agreement with DLS data (25.31nm). SEM images of nanoparticles revealed the spherical shape of particles and the Energy Dispersive X-ray analysis (EDAX) confirmed the significant presence of elemental silver. Synthesized silver nanoparticle showed good fungicidal activity against Didymella bryoniae, Fusarium oxysporum, Aspergillus flavus and Rhizoctonia solani.
\end{abstract}

Keywords- Fungistatic, activity, Phytosynthesis, Silver nanoparticles, Eucalyptus globulus

\section{INTRODUCTION}

The scientific community has oriented towards the field of nanotechnology especially in the research of metal nanoparticles from last few years. The synthesis and applications of nanoparticles gained more importance in the field of chemistry, electronics, cosmetics, textiles industries, drug delivery systems, as biosensors, diagnostics, therapeutics, antimicrobial and environmental remediation [1-4].

Due to high incidence of microbial infections and the growing resistance of pathogens to conventional antimicrobial drugs has created the need for novel antimicrobials. Nanoparticles provide a better alternative and also an interesting tool for material science as well as number of novel applications in biological sciences [5]. Among the metal nanoparticles, silver nanoparticles have gained more importance due to their electrical conductivity, chemical stability, catalytic, optical and antimicrobial properties [6].

Silver is a safe and nontoxic antibacterial agent and has the ability of killing about 650 types of microorganisms which cause diseases in human [7]. Due to their account of increasing antimicrobial property displayed by silver nanoparticles [8], they are projected as future generation antimicrobials [9].
Though the chemical and physical method are available for the synthesis of nanoparticles the green synthesis approach will be nontoxic, ecofriendly, cost effective and single step method which would be suitable for large scale production $[10,11]$. In this method organisms like algae, fungi, bacteria and plants can be utilized in the synthesis silver nanoparticles. Among these plants can be utilized effectively as they are blessed with magical phenomenon of producing bioactive secondary metabolites [1] which act as reducing as well as capping agents in the silver nanoparticles synthesis process [12].

The aim of the experiment was to synthesize silver nanoparticles from the leaf extract of Eucalyptus globulus which is an important tree species easily available and well known for its medicinal uses and test the fungicidal efficacy of the synthesized silver nanoparticles against four (4) fungal pathogens known to cause plant diseases.

\section{II.MATERIALS AND METHODS}

\section{Plants and chemicals}

AR-grade silver nitrate (AgNO3) was purchased from HIMEDIA laboratories and fresh Eucalyptus globulus Labill. Leaves were collected from the University of Mysore 
Manasagangotri campus, Mysuru, Karnataka State, India. Double-distilled water was used for the experiments.

\section{Test fungal pathogens}

Phytopathogens used in the present study namely, Didymella bryoniae, Fusarium oxysporum, Rhizoctania solani and Aspergillus flavus were procured from Department of Studies in Botany, University of Mysore, Manasagangotri, Mysuru, Karnataka State, India.

\section{Preparation of Leaf extract}

Ten grams of fresh leaves were washed with tap water for about two-three times to remove the surface dust particles then with double distilled water. Excess water on the leaf surface was drained out and leaves were cut into small pieces of 0.5 to $1 \mathrm{~cm}$ and boiled with $100 \mathrm{ml}$ of double distilled water for about 10- 15 minutes. Then it is cooled, filtered with muslin cloth followed by filtration in Whatman No. 1 filter paper. Obtained extract was stored at $4{ }^{\circ} \mathrm{C}$ for further use.

\section{Synthesis of Silver nanoparticles}

For the synthesis of silver nanoparticles, Silver nitrate solution of $1 \mathrm{mM}$ concentration was treated with leaf extract in different proportion viz. 9:1, 3:1, 1:1, 1:3 and 1:9 ratios to standardize the metal precursor to plant extract ratio $[13,14]$ and the reaction mixture was kept in dark condition at room temperature. Change of color from yellowish to brown indicated the formation of silver nanoparticles which was further confirmed by UV- visible spectroscopic study. After the completion of reaction, the solution was centrifuged at $12000 \mathrm{rpm}$ for 20 minutes, the obtained silver nanoparticles were dried and stored for further characterization.

\section{Characterization of synthesized silver nanoparticles}

\section{UV-visible spectroscopy}

The small amount of reaction mixture (9:1 ratio) was taken out at regular interval of time after $5 \mathrm{~min}, 1 \mathrm{hr}, 2 \mathrm{hr}, 3 \mathrm{hr}, 4 \mathrm{hr}$, $24 \mathrm{hr}$ and $48 \mathrm{hrs}$ to study the synthesis of silver nanoparticles by measuring the optical density at the wavelength range of 300-700nm using UV-Vis spectrophotometer Beckman Coulter DU730.

\section{Dynamic Light Scattering (DLS) Analysis and Zeta potential}

The average particle size, the distribution and zeta potential were analyzed by Microtrac (USA) particle size analyzer.

\section{XRD analysis}

The crystalline nature of phytosynthesized silver nanoparticles was determined by X-Ray Diffraction (XRD) analysis using Rigaku Destop Miniflex II X-Ray Diffractometer with $2 \theta$ angle 10 to $80^{\circ}$. Further the average particles size was calculated using Debye-Scherrer formula [15-17].

\section{$\mathrm{D}=\mathrm{K \lambda} / \boldsymbol{\beta} \cos \boldsymbol{\theta}$}

Where;

D: Particles size (diameter)

$\mathrm{K}$ : Scherrer coustant $(\mathrm{K}=0.89)$

$\lambda$ : Wavelength of Xray $(0.15406 \mathrm{~nm})$

$\beta$ : Full width at half maximum (FWHM) in radians

$\theta$ : diffraction angle (Bragg's angle $(2 \theta)$

\section{Fourier Transform Infra-red Spectroscopy (FTIR)}

The FTIR investigation of synthesized silver nanoparticles was carried out using Perkin Elmer Spectrum Two Spectrophotometer in the range of 600 to $4000 \mathrm{~cm}-1$ for the analysis of possible bio-reducing and capping agent present in the leaf extract which are responsible for the reduction of the silver ions to silver nanoparticles.

\section{Scanning Electron Microscopy and EDAX analysis}

The morphological characteristics of Eucalyptus globulus leaf extract mediated phytosynthesized silver nanoparticles were studied using Hitachi S-3400N Scanning Electron Microscope (SEM). Images were captured by placing minute amount of nanoparticles on the carbon tape coated over copper grid and sputter coated with gold. Elemental composition and the presence of elemental silver was studied by Energy Dispersive X-ray Spectroscopy (EDAX) using HITACHI (Noran System 7, USA) system attached to SEM.

\section{Fungicidal efficacy of synthesized silver nanoparticles}

Fungicidal efficacy of Eucalyptus globulus leaf extract mediated synthesized silver nanoparticles were tested by agar well diffusion method against Didymella bryoniae, Fusarium oxysporum, Rhizoctania solani and Aspergillus flavus. About $20 \mathrm{ml}$ of Potato dextrose agar medium was poured and allowed to solidify. 100 $\mu 1$ of Seven days old fungal inoculums were uniformly spread over petriplate containing PDA media and $8 \mathrm{~mm}$ wells were punched on the petriplates using sterile cork borer to load the test samples. Then, $100 \mu \mathrm{l}$ of Silver nanoparticles $(1 \mathrm{mg} / \mathrm{ml})$, plant extract, Silvernitrate, DMSO and standard fungicide $(1 \mathrm{mg} / \mathrm{ml})$ with commercial name Sectin (Fenamidone 10\% + Mancozeb $50 \%$ ) were loaded to respective wells. Where, standard Sectin and DMSO was used as positive and negative control respectively. The plates were incubated at room temperature for 3-4 days and zone of inhibition was measured in $\mathrm{mm}$. All tests were carried out in triplicate and repeated thrice. 


\section{Statistical analysis}

All the data was subjected to one-way analysis of variance (ANOVA) using graph pad prism 5 software and represented at $P<0.05$ level of significance.

\section{RESULTS AND DISSCUSSION}

\section{Synthesis of silver nanoparticles}

When $1 \mathrm{mM}$ silver nitrate was added to leaf extract in varying proportions $(9: 1,3: 1,1: 1,1: 3$ and 1:9) and observed for change in color. The change in color from pale yellow to dark brown indicated the reduction of silver ion to silver nanonparticles [18-20] due to excitation of surface Plasmon vibration of metal electrons [21,22] in the reaction mixture with 9:1 ratio and the intensity of color increased with increase in the incubation time. Whereas, no such changes were found in reaction mixtures with other proportions (Figure: 1A) suggesting that 9:1 ratio of metal precursor to leaf extract could be a better proportion for synthesis of silver nanoparticles (Figure: 1B). The phytochemicals present in the leaf extract act both as reducing and stabilizing agent in the synthesis process [23-25].

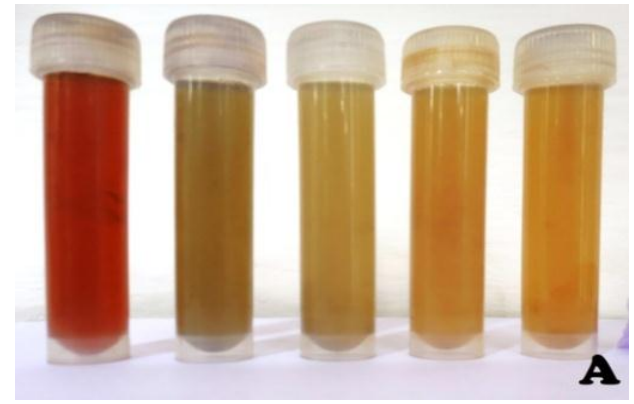

Figure: 1A Showing color change in reaction mixtures with different proportions viz. 9:1, 3:1, 1:1, 1:3 and 1:9 respectively from left to right.

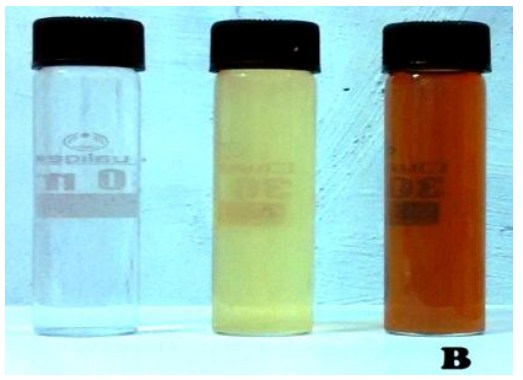

Figure: 1B Silver nitrate (1mM), Leaves extract and Reaction mixture (9:1) respectively from left to right

\section{UV- spectroscopic analysis}

The synthesis of silver nanoparticles was further confirmed by the UV-visible spectroscopy. The reaction mixture with
9:1 proportion of metal precursor to leaf extract showed intense peak at the wavelength between $420 \mathrm{~nm}$ to $440 \mathrm{~nm}$. Whereas no intense peaks were found at particular wavelength in reaction mixture with other proportions (Figure: 2A). Therefore, 9:1 ratio proportion is considered as optimum concentration and further synthesis carried out with same proportion. The intensity of absorbance peak at $425 \mathrm{~nm}$ due surface Plasmon resonance of conductive electrons on metal nanoparticles increased with increase in time from $5 \mathrm{~min}, 1 \mathrm{hr}, 2 \mathrm{hr}, 3 \mathrm{hr}$, $4 \mathrm{hr}, 24 \mathrm{hr}$ and $48 \mathrm{hr}$ with no changes in the wavelength ( Figure: 2B) [26]. Sharp peak and increase in the intensity indicated increase in the nanoparticles formation and intensity of the peak at $24 \mathrm{hr}$ is nearly close to that of $48 \mathrm{hr}$ indicating the completion of reaction [27]. The result corroborates the previous reports where the Surface Plasmon resonance band ranged between $420 \mathrm{~nm}$ to $460 \mathrm{~nm}$ [28-30].

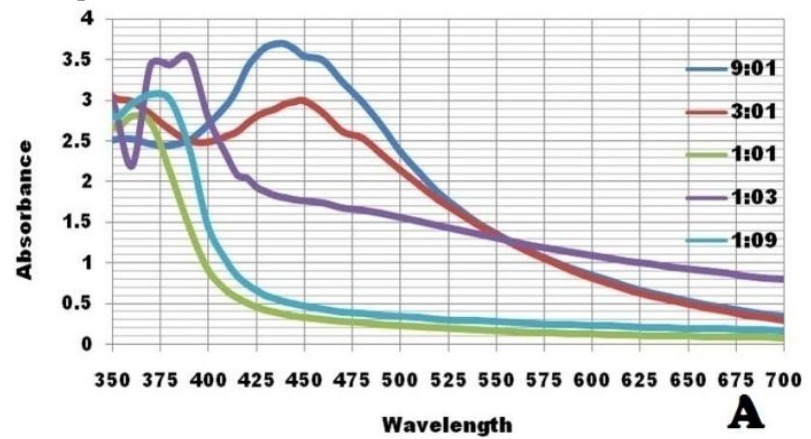

Figure: 2A UV- Visible spectra of reaction mixtures with different ratio

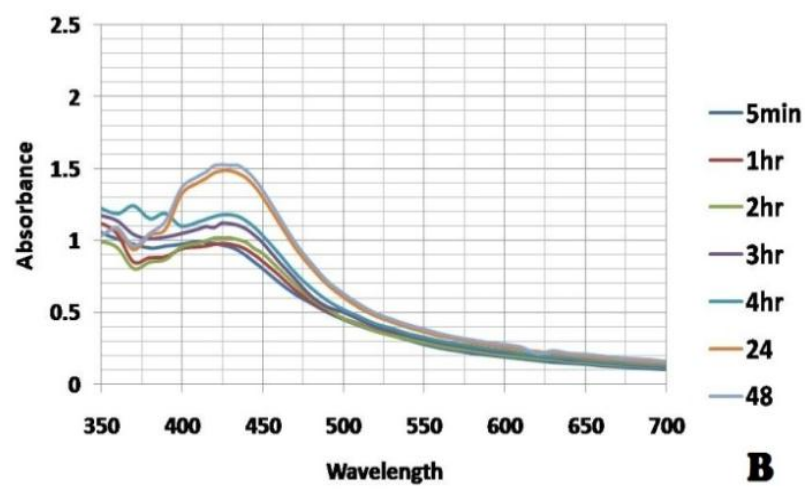

Figure: 2B UV- Visible spectra of reaction mixture (9:1) showing intense peak at $425 \mathrm{~nm}$ at different time interval

\section{Dynamic Light Scattering (DLS) Analysis and Zeta potential}

DLS is an important and reliable technique for analyzing the velocity distribution of particle movement by measuring dynamic fluctuations of light scattering intensity caused by the Brownian motion of the particle [31, 32]. The histogram of the particle size analysis (Figure: 3 ) revealed the average particle size of $25 \mathrm{~nm}$ of phytosynthesized silver 
nanoparticles in colloidal solution. The synthesized nanoparticles showed negative zeta potential of $-7.8 \mathrm{mv}$ which shows the repulsive nature and stability of the particles [33, 34].

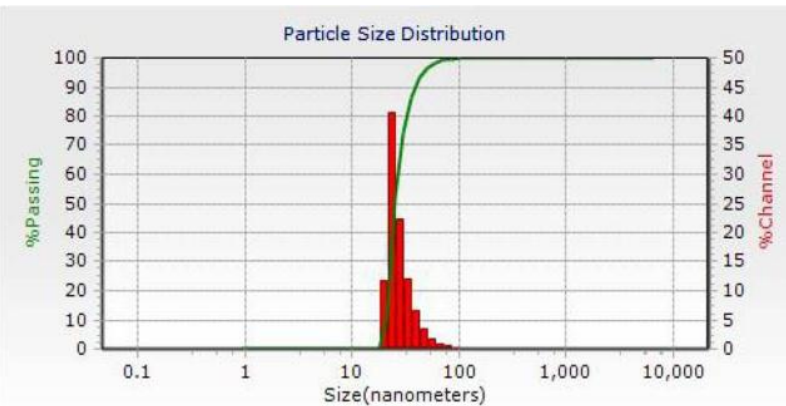

Figure: 3 Histogram of Dynamic light scattering spectroscopy

\section{X-Ray Diffraction Studies}

The peaks obtained by XRD studies (Figure: 4) of synthesized silver nanoparticles at $2 \theta$ angles $38.08^{\circ}, 44.21^{\circ}$, $64.54^{\circ}$ and $77.04^{\circ}$ confirmed that the particles were face centered cubic structure with (111), (200), (220) and (311) planes respectively. The results are in accordance with JCPDS data file no: 04-0783 and other reports [29, 35-38]. Along with above mention peaks some other peaks were also present which may be due to crystallization of organic materials of plant origin [17]. The average particle size of the synthesized nanoparticles calculated using DebyeScherrer's formula was $25.74 \mathrm{~nm}$ which is similar to the obtained DLS result.

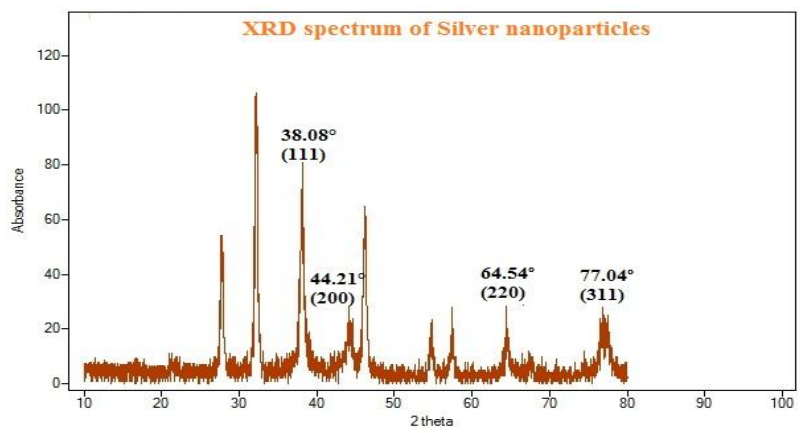

Figure: 4 X-ray diffraction spectra of Eucalyptus globulus leaves extract mediated silver nanoparticles

\section{Fourier Transform Infra-red Spectroscopy (FTIR)}

The Fourier Transform Infra-red spectrum was shown in Figure: 5. The peaks in the spectrum attributed to the possible biomolecules in leaf extract which acts as reducing as well as capping agent $[28,39,40]$. The peak at $2916 \mathrm{~cm}-1$ corresponds to the symmetric stretch of methylene $\mathrm{C}-\mathrm{H}$ group, peak at $2111 \mathrm{~cm}-1$ corresponds to $\mathrm{C} \equiv \mathrm{C}$ of terminal alkyne group, peak at 1611 attributes to the $\mathrm{N}-\mathrm{H}$ bond of primary amine. The peaks at 1036 and 659 may be due to
$\mathrm{CN}$ stretch of primary amine and $\mathrm{C}-\mathrm{H}$ bend of alkyne $/ \mathrm{OH}$ out of plane of alcohol respectively [41, 42].

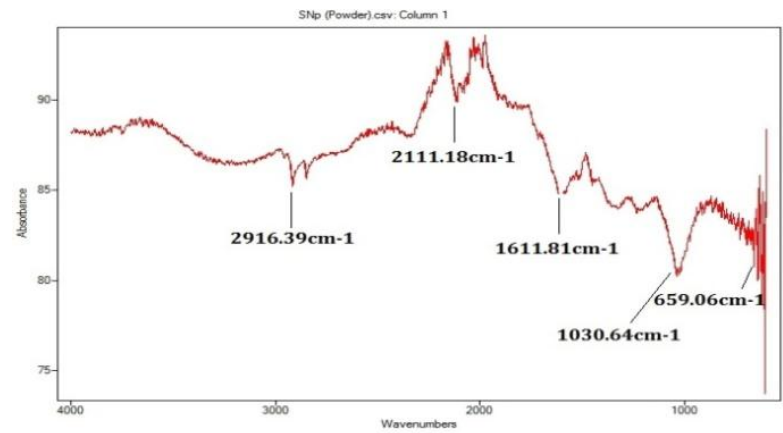

Figure: 5 FTIR spectrum of Phyto-synthesized Silver nanoparticles

\section{Scanning Electron Microscopy and EDX analysis}

The image (Figure: 6A, 6B) of Scanning Electron Microscope clearly showed that the particles are spherical in shape. Strong signals of Silver in the EDAX spectrum (Figure: 7) of synthesized particles confirms $83.20 \%$ silver along with $16.8 \%$ of oxygen content, which may be due to the biomolecules and capping agents attached to the silver nanoparticles which correlates earlier reports [43, 44].

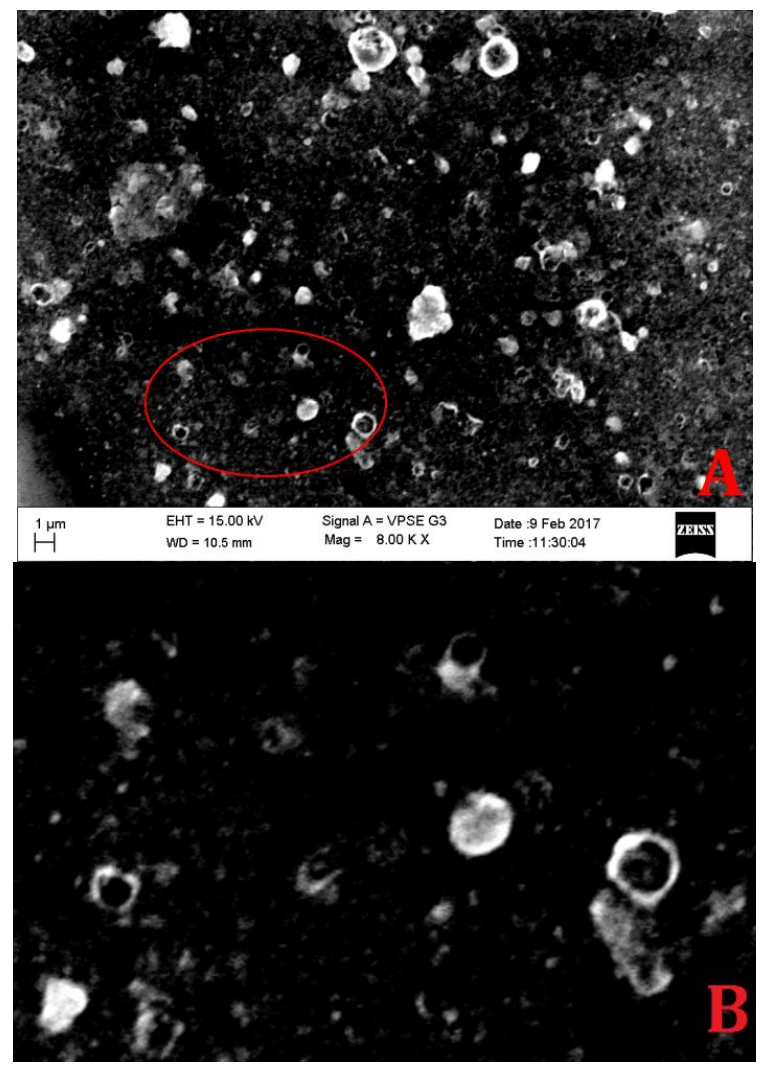

Figure: 6A. Scanning electron microscopic image of silver nanoparticles. 6B Enlarged portion 


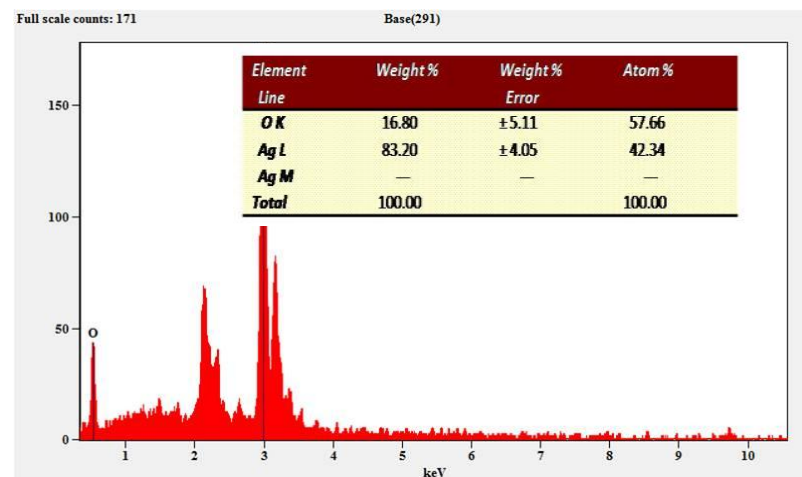

Figure: 7. EDAX spectrum of synthesized silver nanoparticles and elemental composition (insight picture)

\section{Antifungal activity}

The photosynthesized silver nanoparticles proved effective in agar well diffusion method against the tested phytopathogens namely, Didymella bryoniae, Fusarium oxysporum, Rhizoctania solani and Aspergillus flavus. Didymella bryoniae found to be more susceptible to the Silver nanoparticles with inhibition zone of $18.3 \mathrm{~mm}$ than the standard (Sectin) where it showed $10.33 \mathrm{~mm}$ of inhibition (Figure: 8). Aspergillus flavus, Fusarium oxysporum and Rhizoctania solani were also found to be susceptible to synthesized silver nanoparticles with inhibition ozone of $15.3 \mathrm{~mm}, 14.6 \mathrm{~mm}$ and $12.3 \mathrm{~mm}$ respectively which was on par with the standard fungicide Sectin with inhibition zone of $17.3 \mathrm{~mm}, 15.6 \mathrm{~mm}$ and $14.6 \mathrm{~mm}$ respectively (Table: 1 ).

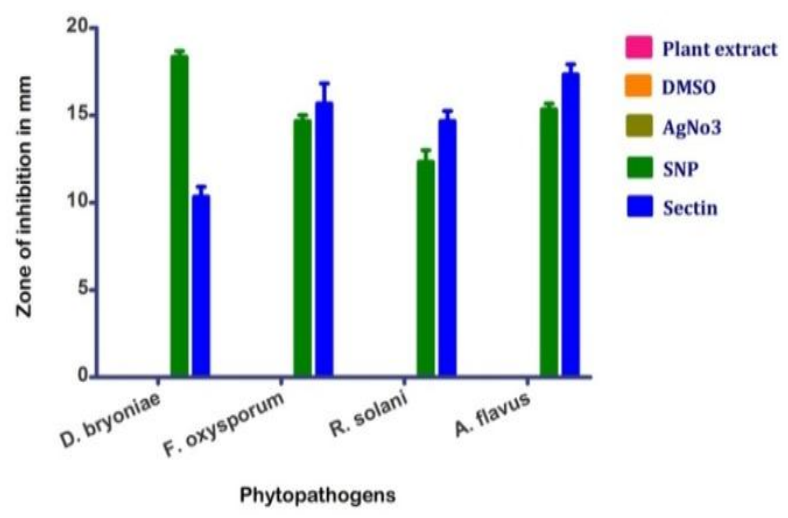

Figure 8 Bar graph of antifungal activity

Table: 1 Antifungal activity of synthesized AgNPs using leaves extract of $\mathrm{E}$. globulus against fungal phytopathogens

\begin{tabular}{|c|c|c|c|c|c|}
\hline Pathogens & \multicolumn{5}{|c|}{ Zone of inhibition in mm } \\
\cline { 2 - 6 } & $\begin{array}{c}\text { Plant } \\
\text { extract }\end{array}$ & DMSO & $\mathrm{AgNO}_{3}$ & SNP & Sectin \\
\hline D. bryoniae & 0 & 0 & 0 & $18.3 \pm 0.33$ & $10.33 \pm 0.33$ \\
\hline F. oxysporum & 0 & 0 & 0 & $14.6 \pm 0.33$ & $15.66 \pm 0.33$ \\
\hline R. solani & 0 & 0 & 0 & $12.3 \pm 0.66$ & $14.66 \pm 0.33$ \\
\hline A. flavus & 0 & 0 & 0 & $15.3 \pm 0.33$ & $17.3 \pm 0.33$ \\
\hline
\end{tabular}

Each value represents the mean \pm SE of three replicates per treatment. $S E=$ Standard error.

\section{CONCLUSION}

Green chemistry approach of synthesizing silver nanoparticles which is known as a green synthesis method is considered as a reliable method of nanoparticle synthesis. It is a simple, easy, economical and eco-friendly method which utilizes biomolecules from plant source as reducing as well as capping agent for the synthesis of nanoparticles. In the present study leaf extract of Eucalyptus globulus was used successfully for synthesis of silver nanoparticles with spherical shape and average particle size of $25 \mathrm{~nm}$. The fungicidal efficacy of synthesized nanoparticles proved to be effective in plant disease management as an alternative or along with conventional synthetic chemical compounds and hence can lead to the minimal use of chemical compounds which may be good sign of eco-friendly approach.

\section{ACKNOWLEDGMENT}

The authors are thankful to UGC, New Delhi, for awarding Rajiv Gandhi National Fellowship to Thejesh Kumar M.P to carryout Ph.D. research work. The authors are also thankful to Institution of Excellence (IOE) and University with Potential for Excellence (UPE) Project Authorities, University of Mysore for extending facilities during the research work.

\section{REFERENCES}

[1]. S.N. Kharat, V.D. Mendhulkar, "Synthesis, characterization and studies on antioxidant activity of silver nanoparticles using Elephantopus scaber leaf extract, Materials Science and Engineering: C, 62, pp.719-724 2016.

[2]. A.G. Ingale, A.N. Chaudhari, "Biogenic synthesis of nanoparticles and potential applications: an eco-friendly approach, Nanomed Nanotechol, 4(165), pp. 1-7, 2013.

[3]. P. Sistani, L. Sofimaryo, Z.R. Masoudi, A. Sayad, R. Rahimzadeh, B. Salehi, A penicillin biosensor by using silver nanoparticles. Int. J. Electrochem. Sci, 9, pp. 6201-6212, 2014.

[4]. F.D. Guerra, M.F. Attia, D.C. Whitehead, F. Alexis, Nanotechnology for environmental remediation: materials and applications. Molecules, 23(7), 1760, 2018.

[5]. N.H. Rao, N. Lakshmidevi, S.V.N. Pammi, P. Kollu, S. Ganapathy, P. Lakshmi, Green synthesis of silver nanoparticles using methanolic root extracts of Diospyros paniculata and their antimicrobial activities. Materials Science and Engineering: C, 62, pp. 553-557. 2016.

[6]. A. Syafiuddin, Salmiati, M.R. Salim, A.B.H. Kueh, T. Hadibarata, H. Nur, A review of silver nanoparticles: Research trends, global consumption, synthesis, properties, and future challenges, Journal of the Chinese Chemical Society, 64(7), pp. 732-756, 2017.

[7]. S.H. Jeong, S.Y. Yeo, S.C. Yi, The effect of filler particle size on the antibacterial properties of compounded polymer/silver fibers. Journal of Materials Science, 40 (20), pp. 5407-5411, 2005.

[8]. O. Choi, K.K. Deng, N. J. Kim, L. Ross Jr, R.Y. Surampalli, Z. $\mathrm{Hu}$, The inhibitory effects of silver nanoparticles, silver ions, and 
silver chloride colloids on microbial growth. Water Research, 42(12), pp. 3066-3074, 2008.

[9]. M. Rai, A. Yadav, A. Gade, Silver nanoparticles as a new generation of antimicrobials. Biotechnology Advances, 27(1), pp. 76-83, 2009.

[10]. H.M.M. Ibrahim, Green synthesis and characterization of silver nanoparticles using banana peel extract and their antimicrobial activity against representative microorganisms. Journal of Radiation Research and Applied Sciences, 8(3), pp.265-275, 2015.

[11]. V. Kumar, S.K. Yadav, Plant-mediated synthesis of silver and gold nanoparticles and their applications. Journal of Chemical Technology \& Biotechnology, 84(2), pp.151-157, 2009.

[12]. J.S. Valli, B. Vaseeharan, Biosynthesis of silver nanoparticles by Cissus quadrangularis extracts. Materials Letters, 82, pp. 171173, 2012.

[13]. G. Karunakaran, M. Jagathambal, A Gusev, E. Kolesnikov, A.R. Mandal, D. Kuznetsov, Allamanda cathartica flower's aqueous extract-mediated green synthesis of silver nanoparticles with excellent antioxidant and antibacterial potential for biomedical application. MRS Communications, 6(1), pp.41-46. 2016.

[14]. S. Anjum, B.H. Abbasi, Biomimetic synthesis of antimicrobial silver nanoparticles using in vitro-propagated plantlets of a medicinally important endangered species: Phlomis bracteosa. International Journal of Nanomedicine, 11, 1663, 2016.

[15]. Y. He et al., Green synthesis of silver nanoparticles by Chrysanthemum morifolium Ramat. extract and their application in clinical ultrasound gel. International Journal of Nanomedicine, 8, 1809, 2013.

[16]. A. Saxena, R.M. Tripathi, F. Zafar, P. Singh, Green synthesis of silver nanoparticles using aqueous solution of Ficus benghalensis leaf extract and characterization of their antibacterial activity. Materials letters, 67(1), pp.91-94, 2012.

[17]. Gomathi, P.V. Rajkumar, A. Prakasam, K. Ravichandran, Green synthesis of silver nanoparticles using Datura stramonium leaf extract and assessment of their antibacterial activity. ResourceEfficient Technologies, 3(3), pp.280-284, 2017.

[18]. G. Lakshmanan, A. Sathiyaseelan, P.T. Kalaichelvan, K. Murugesan, Plant-mediated synthesis of silver nanoparticles using fruit extract of Cleome viscosa L.: Assessment of their antibacterial and anticancer activity. Karbala International Journal of Modern Science, 4(1), pp.61-68, 2018

[19]. A.M. Awwad, N.M. Salem, A.O. Abdeen, Green synthesis of silver nanoparticles using carob leaf extract and its antibacterial activity. International Journal of Industrial Chemistry, 4(1), 29, 2013

[20]. N. Durán, P.D. Marcato, O.L. Alves, G.I. De Souza, G. I, E. Esposito, Mechanistic aspects of biosynthesis of silver nanoparticles by several Fusarium oxysporum strains. Journal of Nanobiotechnology, 3(1), 8, 2005.

[21]. L. Swarnalatha, C. Rachela, P. Ranjan, P. Baradwaj, Evaluation of invitro antidiabetic activity of Sphaeranthus amaranthoides silver nanoparticles. Int. J. Nanomater. Biostruct, 2(3), pp.25-29.2012.

[22]. M.V. Kiran, S. Murugesan, Biogenic silver nanoparticles by Halymenia poryphyroides and its in vitro anti-diabetic efficacy. Journal of Chemical and Pharmaceutical Research, 5(12), pp.1001-1008, 2013.
[23]. C. Ramteke, T. Chakrabarti, B.K. Sarangi, R. A. Pandey, Synthesis of silver nanoparticles from the aqueous extract of leaves of Ocimum sanctum for enhanced antibacterial activity. Journal of Chemistry, 2013(2012).

[24]. P. Kuppusamy, M.M. Yusoff, G.P. Maniam, N. Govindan, Biosynthesis of metallic nanoparticles using plant derivatives and their new avenues in pharmacological applications-An updated report. Saudi Pharmaceutical Journal, 24(4), pp.473-484, 2016.

[25]. S. Rajakannu, S. Shankar, S. Perumal, S. Subramanian, G.P. Dhakshinamoorthy, Biosynthesis of silver nanoparticles using Garcinia mangostana fruit extract and their antibacterial, antioxidant activity. Int. J. Curr. Microbiol. Appl. Sci, 4, pp.944952, 2015.

[26]. P. Logeswari, S. Silambarasan, J. Abraham, Synthesis of silver nanoparticles using plants extract and analysis of their antimicrobial property. Journal of Saudi Chemical Society, 19(3), pp.311-317, 2015.

[27]. N. Ahmad, et al., Rapid synthesis of silver nanoparticles using dried medicinal plant of basil. Colloids and Surfaces B: Biointerfaces, 81(1), pp.81-86, 2010

[28]. S. Arokiyaraj, S. Vincent, M. Saravanan, Y. Lee, Y.K. Oh, K.H. Kim, Green synthesis of silver nanoparticles using Rheum palmatum root extract and their antibacterial activity against Staphylococcus aureus and Pseudomonas aeruginosa. Artificial cells, Nanomedicine, and Biotechnology, 45(2), pp.372-379, 2017.

[29]. H. Singh, J. Du, T.H. Yi, Kinneretia THG-SQI4 mediated biosynthesis of silver nanoparticles and its antimicrobial efficacy. Artificial cells, Nanomedicine, and Biotechnology, 45(3), pp. 602-608, 2017.

[30]. N. Ahmad, S. Sharma, Green synthesis of silver nanoparticles using extracts of Ananas comosus. Green and Sustainable Chemistry, 2(04), 141, 2012.

[31]. R.C. Murdock, L. Braydich-Stolle, A.M. Schrand, J.J. Schlager, S.M. Hussain, Characterization of nanomaterial dispersion in solution prior to in vitro exposure using dynamic light scattering technique. Toxicological Sciences, 101(2), pp.239-253, 2008.

[32]. M.B. Kasture, P. Patel, A.A. Prabhune, C.V. Ramana, A.A. Kulkarni, B.L.V. Prasad, Synthesis of silver nanoparticles by sophorolipids: Effect of temperature and sophorolipid structure on the size of particles. Journal of Chemical Sciences, 120(6), pp. 515-520, 2008.

[33]. H.P. Borase, C.D. Patil, R.B. Salunkhe, C.P. Narkhede, B.K. Salunke, S.V. Patil, Phyto-synthesized silver nanoparticles: a potent mosquito biolarvicidal agent. Journal of Nanomedicine and Biotherapeutic Discovery, 3, pp.1-7, 2013.

[34]. K. Anandalakshmi, J. Venugobal, V. Ramasamy, Characterization of silver nanoparticles by green synthesis method using Pedalium murex leaf extract and their antibacterial activity. Applied Nanoscience, 6(3), pp.399-408, 2016.

[35]. M.K. Swamy, M.S. Akhtar, S.K. Mohanty, U.R. Sinniah, Synthesis and characterization of silver nanoparticles using fruit extract of Momordica cymbalaria and assessment of their in vitro antimicrobial, antioxidant and cytotoxicity activities. Spectrochimica Acta Part A: Molecular and Biomolecular Spectroscopy, 151, pp.939-944, 2015.

[36]. D. Mukundan, R. Mohankumar, R. Vasanthakumari, Green synthesis of silver nanoparticles using leaves extract of Bauhinia 
tomentosa linn and its invitro anticancer potential. Materials Today: Proceedings, 2(9), pp.4309-4316, 2015.

[37]. A.S. Lanje, S.J. Sharma, R.B. Pode, Synthesis of silver nanoparticles: a safer alternative to conventional antimicrobial and antibacterial agents, J Chem Pharm Res, 2(3), pp.478-483, 2010.

[38]. M.M. Khalil, E.H. Ismail, K.Z. El-Baghdady, D Mohamed, Green synthesis of silver nanoparticles using olive leaf extract and its antibacterial activity. Arabian Journal of Chemistry, 7(6), pp.1131-1139, 2014.

[39]. D.G. Sant et al., Adiantum philippense L. frond assisted rapid green synthesis of gold and silver nanoparticles. Journal of Nanoparticles, 2013.

[40]. S.J.P. Jacob, J.S. Finub, A. Narayanan, Synthesis of silver nanoparticles using Piper longum leaf extracts and its cytotoxic activity against Hep-2 cell line. Colloids and Surfaces B: Biointerfaces, 91, pp.212-214, 2012.

[41]. J. Coates, Interpretation of infrared spectra, a practical approach. Encyclopedia of Analytical Chemistry, 12, pp.1081510837, 2000

[42]. J.B. Lambert, H.F. Shurvell, D.A. Lightner, R.G. Cooks, Introduction to organic spectroscopy. Macmillan Publishing Company. Pp.174-177, 1987.

[43]. B.A. Milaneze et al., Facile synthesis of monodisperse gold nanocrystals using Virola oleifera, Nanoscale Research Letters, 11(1), 465, 2016.

[44]. R.S. Isaac, G. Sakthivel, C.H. Murthy, Green synthesis of gold and silver nanoparticles using Averrhoa bilimbi fruit extract. Journal of Nanotechnology, 2013 